\title{
Development and Validation of Analytical Method for Quantification of Losartan Potassium in Solid Dosage Form
}

Latif $A^{*}$, Akbar F, Khan AJ, Shafi $H$ and Mazhar M

Head of Department, University College of Pharmacy, Pharmaceutical Chemistry, Allama Iqbal Campus, University of the Punjab, Lahore, Punjab, Pakistan

\begin{abstract}
The aim of this study was to develop and validate a simple, robust, reliable and an accurate isocratic reverse phase high-performance liquid chromatography (RP-HPLC) method for quantification of Losartan potassium in solid dosage form using DAD Detector. Elution was carried out with mobile phase comprising of $0.01 \mathrm{M}$ monobasic potassium dihydrogen phosphate buffer (adjusted at pH $3.0 \pm 0.05$ with ortho-phosphoric acid) and methanol (40: $60)$, through octadecyl silyl (C18) column $(15 \mathrm{~cm} \times 4.6 \mathrm{~mm} \times 5 \mu \mathrm{l})$, at flow rate of $1 \mathrm{ml} / \mathrm{min}$. The detection was carried out at $230 \mathrm{~nm}$. The developed method was validated according to International Conference on Harmonization $(\mathrm{ICH})$ guidelines $(\mathrm{ICH} 2005)$. The assay was linear in concentration range of $1-3 \mu \mathrm{gmL}^{-1}$ with Correlation coefficient of 0.999 . The limit of detection was $0.036 \mu \mathrm{gmL}^{-1}$ and limit of quantification was $0.110 \mu \mathrm{g} / \mathrm{ml}$. Similarly, method accuracy was asses by comparing the \%RSD of BP method with the \%RSD of the method developed which shows RSD for standard method was $1.012 \%$ while for developed method it was $1.516 \%$ and combined RSD of both two methods was found $1.823 \%$ that was as per the precision criteria of accuracy i.e. $<2 \%$. The result of intraday study was $0.129 \%$ and Intermediate precision among inter day and brand to brand was $0.332 \%$. Moreover, the devised method seems to be linear over broad range of LK concentration $\left(1-3 \mu \mathrm{gmL}^{-1}\right)$ with appreciable repeatability and reproducibility $(\mathrm{RSD}<2.00)$.
\end{abstract}

The results of present study indicate that the method is efficient, specific, sensitive and suitable to be used for the determination of losartan potassium in solid dosage forms using isocratic mode in comparison to gradient mode used by United States pharmacopoeia (USP 2016).

Keywords: RP-HPLC-DAD; ICH guidelines; Losartan potassium; Method development; Validation

\section{Introduction}

Losartan potassium (LK) is an orally active, non-peptide angiotensin II receptor antagonist. Because of effect of consequently reduced pressure of angiotensin II and Angiotensin-1 receptors selectively blockade, losartan is introduced for clinical usage in "Hypertension" as a new class drug [[1,2].

In clinical trials, dizziness was the only drug-related event reported more frequently with LK monotherapy. Combined dosage form of hydrochlorothiazide (diuretic) and Losartan is mostly used due to its highly anti-hypertensive action. To maintain plasma drug concentration, tablet should be taken 3-4 times. For the treatment of hypertension, LK is considered as most desirable drug as it developed a sustained release drug delivery system. Hence, current study reflects an attempt to develop and validate an appropriate quantification method for losartan potassium in dosage form.

LK is a potassium salt of biphenyl tetrazole is widely used for the treatment of hypertension and diabetic nephropathy [3]. Chemically polar nature of LK renders it very reactive i.e. easily protonated even under mild reaction or stress conditions and resultant molecules usually undergo addition reactions to form dimers while eliminating side chains of alkyl or halogen group. Although much work had been done for the determination of LK using state-of-the art analytical techniques however, literature lacks simple and pragmatic method to study the behavior of LK towards storage and processing conditions.

United States Pharmacopoeia (USP 2016) used a gradient method consisting of solution A (acetonitrile: pH 7.0 buffer of monobasic potassium phosphate and dibasic sodium phosphate) (15:85) and Solution B (acetonitrile). Chromatographic conditions are $1.0 \mathrm{ml} / \mathrm{min}$ flow rate, L7 column packing $(5 \mu \mathrm{m}, 15 \mathrm{~cm} \times 3.9 \mathrm{~mm})$, UV detector wavelength $250 \mathrm{~nm}$, injection volume $10 \mu \mathrm{l}, 0.25 \mathrm{mg} / \mathrm{ml}$ of Standard solution and sample solutions are prepared by using Solution A as diluent. USP used gradient elution mode whereas the authors of this study developed analytical method on isocratic mode. Schellinger suggested avoiding gradient elution over isocratic mode because gradient mode requires more re-evaluation and isocratic mode is preferred in case of separation of single component or maximum for the separation of less than ten components.

Dos Passos et al. used an isocratic HPLC method for LK tablets assay. In this method he used L7 column packing $(5 \mu \mathrm{m}, 15 \mathrm{~cm}$ $\mathrm{x} 4.6 \mathrm{~mm}$ ), triethylamine solution $(0.5 \%)$ having $\mathrm{pH}$ of 2.4 and acetonitrile 60: $40(\mathrm{v} / \mathrm{v})$ as mobile phase having flow rate was $1 \mathrm{ml} /$ min, sample injection volume of $20 \mu \mathrm{l}$ and the peak response was determined at the wavelength of $225 \mathrm{~nm}$ through photo diode array (PDA) detector in the concentration range of $15-45 \mu \mathrm{g} / \mathrm{ml}$ with $\mathrm{R}$-value of 0.999 . The $\mathrm{pH} 2.4$ used by them was highly dangerous for stability of stationary phase of the column. Therefore, authors of the current study used the $\mathrm{pH} 3.0$ buffer in mobile phase and methanol (60: $40 \mathrm{v} / \mathrm{v})$ which is comparatively safer $\mathrm{pH}$ for column stationary phase. Further, they performed forced degradation study by acid, base and peroxides for very short duration of 2 hours but authors of this study performed it for 24 hours [4].

*Corresponding author: Abida Latif, Head of Department, University College of Pharmacy, Pharmaceutical Chemistry, Allama Iqbal Campus, University of the Punjab, Lahore, Punjab, Pakistan, E-mail: abidalatifanwar@gmail.com

Received July 01, 2018; Accepted July 23, 2018; Published July 30, 2018

Citation: Latif A, Akbar F, Khan AJ, Shafi H, Mazhar M (2018) Development and Validation of Analytical Method for Quantification of Losartan Potassium in Solid Dosage Form. Pharm Anal Acta 9: 592. doi: 10.4172/2153-2435.1000592

Copyright: (c) 2018 Latif A, et al. This is an open-access article distributed under the terms of the Creative Commons Attribution License, which permits unrestricted use, distribution, and reproduction in any medium, provided the original author and source are credited. 
Kathiresan et al. used a method for analysis using C-18 Spherisorb ODS column $(5 \mu \mathrm{l}, 25 \mathrm{~cm} \times 4.6 \mathrm{~mm}), 254 \mathrm{~nm}$ wavelength, $20 \mu \mathrm{l}$ injection volume, $1.5 \mathrm{ml} / \mathrm{min}$ flow rate and $20 \mathrm{~min}$ run-time. The mobile phase used was premixed ammonium dihydrogen acetonitrile and phosphate buffer having pH 3.0 (35: 65). They reported that LK peak was eluted at 7.5 min whereas, in current study, the peak of LK was eluted at 5 $\pm 1 \mathrm{~min}$. Therefore, the authors reported method is faster under the current method developed and which can save time as well as cost of analysis [5].

A simultaneous determination method for LK and ramipril was developed and validated by Rao and Srinivas. They used hypersil ODS C18 column $(4.6 \times 250 \mathrm{~mm}, 5 \mu \mathrm{m})$ and mobile phase acetonitrile: methanol: $10 \mathrm{mM}$ tetra butyl ammonium hydrogen sulphate in water (30: $30: 40 \% \mathrm{v} / \mathrm{v} / \mathrm{v}$ ) in isocratic elution mode. The flow rate was and effluent were set at $1.0 \mathrm{ml} / \mathrm{min}$ and $210 \mathrm{~nm}$ wavelength, respectively. They reported the retention times for LK and ramipril as 4.7 and $3.3 \mathrm{~min}$, respectively. The drawback of their study was the use of ion-pairing agent (tetra butyl ammonium hydrogen sulphate). The ion-pairing agents interferer with stationary phase and cannot be completely washed from the column even with extensive column flushing. Therefore, such column cannot be used for other methods for analysis [6].

Therefore, there is an inevitable necessity to develop and validate a method for analysis of LK that will be simple, sensitive, fast and robust. The outcomes of the current study will provide an expedient and pragmatic high-performance liquid chromatography (HPLC) method for determination of LK in solid dosage form.

\section{Materials and Method}

\section{Standards, samples, reagents and chemicals}

The certified reference material of Losartan potassium (LK) was procured from United States Pharmacopoeia (USP Catalogue \#1370462, Batch \# H1M331). Two commercial brands of LK (25 mg per tablet) marketed under brand names A2A (Wilson's Pharmaceuticals, Islamabad-Pakistan) and Eziday (Werrick Pharmaceuticals, KarachiPakistan) were purchased from local market of Lahore-Pakistan. High-Performance Liquid Chromatography (HPLC) grade methanol was purchased from VWR Chemicals while ortho-phosphoric acid and monobasic potassium phosphate (Lot \# C1790) was supplied by Honeywell (Seelze, Germany).

\section{Preparation of mobile phase and diluent}

Mobile phase contained monobasic potassium phosphate buffer $(1.36 \mathrm{mg} / \mathrm{ml}) \mathrm{pH} 3$ and methanol $(40: 60 \mathrm{v} / \mathrm{v})$. The $\mathrm{pH}$ of buffer was adjusted to 3.0 with phosphoric acid. Diluent was prepared using methanol and phosphate buffer of $\mathrm{pH} 3.0(50: 50 \mathrm{v} / \mathrm{v})$.

\section{Preparation of standard stock solution of LK $(0.1 \mathrm{mg} / \mathrm{mL})$}

Weighed accurately $10 \mathrm{mg}$ of LK standard and transferred it to a $100 \mathrm{ml}$ volumetric flask. Dissolved the contents in small amount of diluent with sonication. Final volume was made up to the mark using diluent. Filtered it through $0.45 \mu \mathrm{m}$ syringe filter.

\section{Preparation of test sample solution}

Powdered tablets containing $10 \mathrm{mg}$ of LK was accurately weighed and powder transferred it to a $100 \mathrm{ml}$ volumetric flask. Dissolved the contents in small amount of diluent with sonication. Final volume was made up to the mark using diluent. Filtered it through $0.45 \mu \mathrm{m}$ syringe filter.

\section{Chromatographic conditions}

The samples and standards were analyzed using HPLC (Waters, Alliance e2695 separation module) equipped with Photo Diode Array (PDA) detector (waters 2998) and Spherisorb column of packing ODS-2 $(5 \mu \mathrm{m}, 150 \mathrm{~mm} \times 4.6 \mathrm{~mm})$. Mobile phase comprising ratio $(60: 40 \mathrm{v} / \mathrm{v})$ of methanol and $\mathrm{KH}_{2} \mathrm{PO}_{4}$ buffer adjusted to $\mathrm{pH} 3.0$ using orthophosphoric acid. Flow rate was isocratic at $1 \mathrm{ml} / \mathrm{min}$. Column temperature was set at ambient. Injection volume was set at $20 \mu \mathrm{l}$ and eluted compounds were seen at $230 \mathrm{~nm}$ fixed wavelength as well as scanned over range of $190 \mathrm{~nm}-400 \mathrm{~nm}$ to characterize impurities or degradants by using diode array detector. The chromatographic data obtained thus was processed using Empower 3 software.

\section{Method Validation}

Authors of this manuscript validated the developed method in accordance with International conference of Harmonization validation guidelines [7].

\section{Linearity}

Linearity was determined using five concentration levels. Each level was run in duplicate for five days. The linearity of developed HPLC method was acquired over wide range of concentration of 1-3 $\mu \mathrm{g} / \mathrm{mL}$ as most of the pharmaceutical dosage forms are found in this range. Pharmaceutical formulations are not intended to have very high concentration of active ingredient, while this method is used to design the analyte LK in solid dosage forms.

\section{Detection limit (DL) and quantification limit (QL)}

LOD is typically the three times of the noise level and LOQ gives signal to noise ratio of ten times. Response was checked at different concentrations $(1,1.5,2,2.5$ and $3 \mu \mathrm{g} / \mathrm{mL})$. A calibration curve between concentrations and response was then drawn in order to find out the $y$-intercept value using Pearson coefficient of correlation (r), LOD and LOQ by using linear regression equation.

$$
\begin{aligned}
& \mathrm{LOD}=3 \mathrm{SD} / \mathrm{S} \\
& \mathrm{LOQ}=10 \mathrm{SD} / \mathrm{S}
\end{aligned}
$$

\section{Precision}

The degree of closeness of outputs among successive attempts to measure amount in analysis obtained under the constant conditions from different sampling of the same stock solution which is very homogeneous showed the precision of our analytical method under test.

\section{Selectivity}

To determine the selectivity of developed method for LK in standard as well as in pharmaceutical products, purity angle and threshold value was compared and further assured through 3D spectra acquired from PDA (190-400 nm).

\section{Forced degradation}

The forced degradation was performed following a previously documented method of Blessy, Patel et al. $10 \mathrm{mg}$ of LK standard and an equal amount of LK samples taken from pooled tablets of both brands (A2A and Eziday) were subjected to thermal hydrolysis, photodegradation, acid hydrolysis, base hydrolysis and forced oxidation observing conditions as shown in Table 1. All the samples were processed for the data generation after 24 hours incubation under above mentioned conditions. All tests and controls (except thermal hydrolysis and UV test) were processed in dark chamber [8]. 
Citation: Latif A, Akbar F, Khan AJ, Shafi H, Mazhar M (2018) Development and Validation of Analytical Method for Quantification of Losartan Potassium in Solid Dosage Form. Pharm Anal Acta 9: 592. doi: 10.4172/2153-2435.1000592

Page 3 of 6

\section{Robustness}

It is a measure of capacity of an analytical procedure to remain unaffected by small deliberate variations in method parameters and provides an indication of its reliability during normal usage.

\section{Accuracy}

Accuracy is a crucial part of the method validation. It is the closeness of agreement between observed results through selected analytical procedure and true value.

\section{Results and Discussion}

The present study was designed to develop a validated, simple and reliable HPLC method using PDA detector for the quantitative analysis of LK. Initially, the analytical and instrumental parameters were optimized to establish a well resolved peaks of LK standard.

\section{Linearity}

In order to assess the linearity of devised assay, the detector response was plotted versus concentrations and was found to be linear over $1-3 \mu \mathrm{g} / \mathrm{mL}$ (Figure 1 ). The observed values of regression coefficient $\left(\mathrm{R}^{2}\right)$ i.e. 0.999 fits well over the ICH Guideline (2005). Although, a large number of studies has been conducted to analyze LK in various pharmaceutical formulations but linearity of these assays was with relatively smaller coefficient of determination $\left(\mathrm{R}^{2}\right)$.

\section{Limit of detection and quantification}

The results for LOD and LOQ determination are shown in Table 2. The LOD and LOQ determined for LK using the current method was 0.0364 and 0.110 respectively. Therefore, the current developed method is sensitive as compared to previously reported methods.

\section{Precision}

Hossen, Haque et al. calculated \% RSD for precision as $<0.5$. The purpose of current study is to offer authentication that results obtained from different successive measurements are very close to each other under the same conditions [9].

This study is conducted by preparing six fresh replicates of $100 \%$ concentration of homogenized mixture of sample and proceeds the

\begin{tabular}{|c|c|c|}
\hline SL. No. & Condition & Procedure \\
\hline 1 & Thermal Hydrolysis & $80^{\circ} \mathrm{C}$ and $75 \%$ relative humidity for 24 hours \\
\hline 2 & Photo Degradation & $\begin{array}{c}254 \mathrm{~nm} \text { UV lamp on closed chamber for } 24 \\
\text { hours }\end{array}$ \\
\hline 3 & Acid Hydrolysis & Treated with $\mathrm{N} / 10 \mathrm{H}_{2} \mathrm{SO}_{4}$ for 24 hours \\
\hline 4 & Base Hydrolysis & Treated with $\mathrm{N} / 10 \mathrm{NaOH}$ for 24 hours \\
\hline 5 & Induced Oxidation & Treated with $3 \% \mathrm{H}_{2} \mathrm{O}_{2}$ for 24 hours \\
\hline
\end{tabular}

Table 1: Conditions followed for forced degradation of Losartan potassium (LK).

\section{Linearity curve for LK}

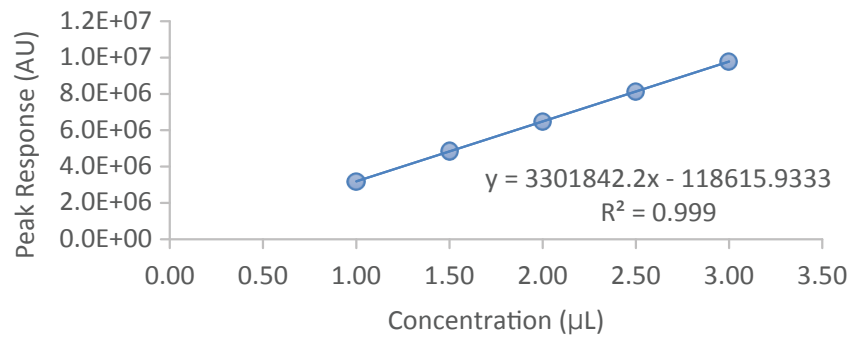

Figure 1: Linearity Curve for LK. intermediate precision among day to day (inter-day and intra-day) and brand to brand. Results are shown in Tables 3 and 4 .

\section{Repeatability and Reproducibility of Developed HPLC Based Stability Indicating Assay}

\section{Selectivity, specificity and degradation study}

Selectivity and specificity of the method for losartan Potassium was evaluated through PDA (photodiode array detector) by comparing purity angle with threshold value. Lower the purity angle from threshold value confirms the selectivity of method for our specified analyte present in different brands (Eziday and A2A) [10-13]. Effect of various stress factors on standard that caused degradation was also evaluated on selectivity of the method through purity angle threshold value comparison. All these values confirmed the selectivity of the method even in the presence of degradation or impurities as given in Table 5 and their purity plots are given in Figures 2-7.

\section{Robustness of method}

Robustness of method is evaluated through minor but deliberate changes in method and measured the ability of method remained unaffected from these changes. These deliberate changes were in flow rate, mobile phase and temperature variations. In the validated method flow rate was varied from $0.8 \mathrm{ml} / \mathrm{min}$ to $1.2 \mathrm{ml} / \mathrm{min}$, mobile phase $\mathrm{pH}$ up to 3.2

\begin{tabular}{|c|c|c|c|c|c|}
\hline SL. No. & $\begin{array}{c}\text { Conc. } \\
(\mu \mathrm{g} / \mathrm{mL})\end{array}$ & $\begin{array}{c}\text { Linear } \\
\text { regression } \\
\text { Equation }\end{array}$ & $\mathbf{R}^{\mathbf{2}}$ & Y-Intercept & Slope \\
\hline Std.01 & $1-3$ & $\begin{array}{c}y=3300918.8 x \\
-115803\end{array}$ & $\mathrm{R}^{2}=0.99999898$ & 3300918.8 & 115803 \\
\hline Std.02 & $1-3$ & $\begin{array}{c}y=3300417.6 x \\
-117774.6\end{array}$ & $\mathrm{R}^{2}=0.99999541$ & 3300417.6 & 117774.6 \\
\hline Std.03 & $1-3$ & $\begin{array}{c}y=3304190.2 x \\
-122270.2\end{array}$ & $\mathrm{R}^{2}=0.99999782$ & 3304190.2 & 122270.2 \\
\hline Std.04 & $1-3$ & $\begin{array}{c}y=3302329.2 x \\
-121679.2\end{array}$ & $\mathrm{R}^{2}=0.99999038$ & 3302329.2 & 121679.2 \\
\hline Std.05 & $1-3$ & $\begin{array}{c}y=3301659.8 x \\
-118893.8\end{array}$ & $R^{2}=0.99999827$ & 3301659.8 & 118893.8 \\
\hline Mean & & & & 1315.077 & 119284.16 \\
\hline SD & & & & \\
\hline
\end{tabular}

Table 2: LOD and LOQ determination for LK.

\begin{tabular}{|c|c|c|c|c|}
\hline \multirow{2}{*}{ Days } & Brands & $\begin{array}{c}\text { \%RSD of } \\
\text { retention time }\end{array}$ & $\begin{array}{c}\text { \%RSD of } \\
\text { peak area }\end{array}$ & $\begin{array}{c}\text { \%RSD of } \\
\text { assay }\end{array}$ \\
\hline \multirow{2}{*}{ Day - 01 } & Brand-01 & 0.132 & 0.308 & 0.233 \\
\cline { 2 - 5 } & Brand-02 & 0.033 & 0.140 & 0.128 \\
\hline \multirow{2}{*}{ Day - 02 } & Brand-01 & 0.042 & 0.131 & 0.129 \\
\cline { 2 - 5 } & Brand-02 & 0.043 & 0.156 & 0.151 \\
\hline RSD & & $\mathbf{0 . 1 4 9}$ & $\mathbf{0 . 3 9 5}$ & $\mathbf{0 . 3 3 2}$ \\
\hline
\end{tabular}

Table 3: Inter-day and Brand to Brand-Intermediate Precision.

\begin{tabular}{|c|c|c|c|c|}
\hline Conc. & \multicolumn{2}{|c|}{ Intraday (n=6) } & \multicolumn{2}{c|}{ Inter-day (n=6) } \\
\hline$(\mathrm{mg} / \mathrm{ml})$ & \%Assay & Precision & \%Assay & Precision \\
\hline 0.1 & 99.115 & 0.129 & 98.780 & 0.160 \\
\hline
\end{tabular}

Table 4: Inter-day \& Intra-day Precision.

\begin{tabular}{|c|c|c|c|c|c|}
\hline Sample & RT & Area & Purity angle & $\begin{array}{c}\text { Threshold } \\
\text { value }\end{array}$ & Peak purity \\
\hline THR & 5.497 & 3018283 & 0.036 & 0.238 & Pure \\
\hline Photo & 5.689 & 2908292 & 0.036 & 0.237 & Pure \\
\hline Acidic & 5.670 & 2759760 & 0.033 & 0.235 & Pure \\
\hline Basic & 5.702 & 2579636 & 0.031 & 0.238 & Pure \\
\hline Oxidation & 5.708 & 2748721 & 0.038 & 0.235 & Pure \\
\hline
\end{tabular}

Table 5: Detection of Selectivity. 


\section{Purity Plot}

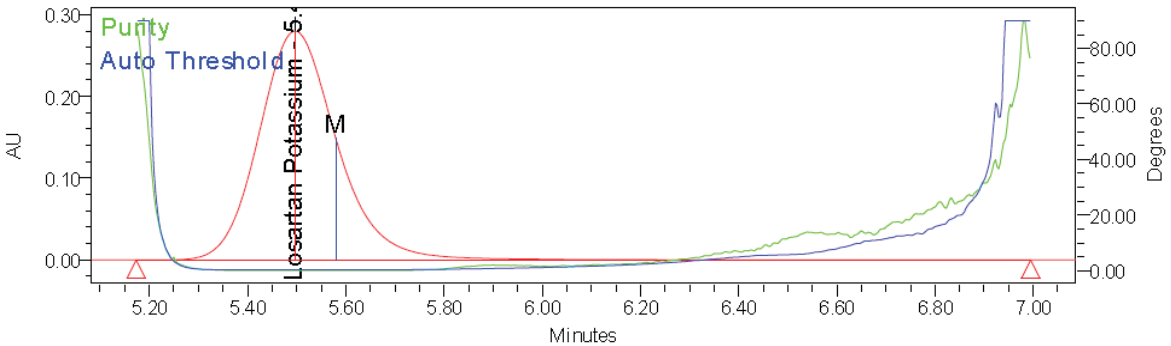

Figure 2: Thermal Stress-Purity plot (Green line showed purity angle, Blue line showed purity threshold, Purity angle $<$ Purity threshold means peak is pure).

\section{Purity Plot}

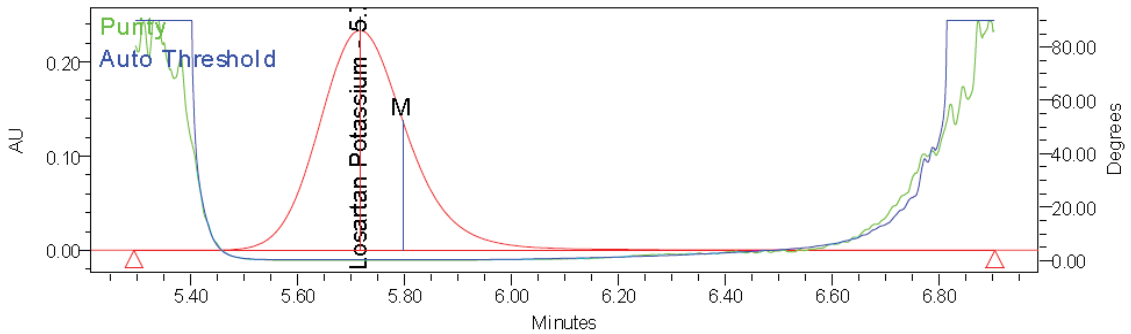

Figure 3: UV Stress-Purity plot (Green line showed purity angle, Blue line showed purity threshold, Purity angle $<$ Purity threshold means peak is pure).

\section{Purity Plot}

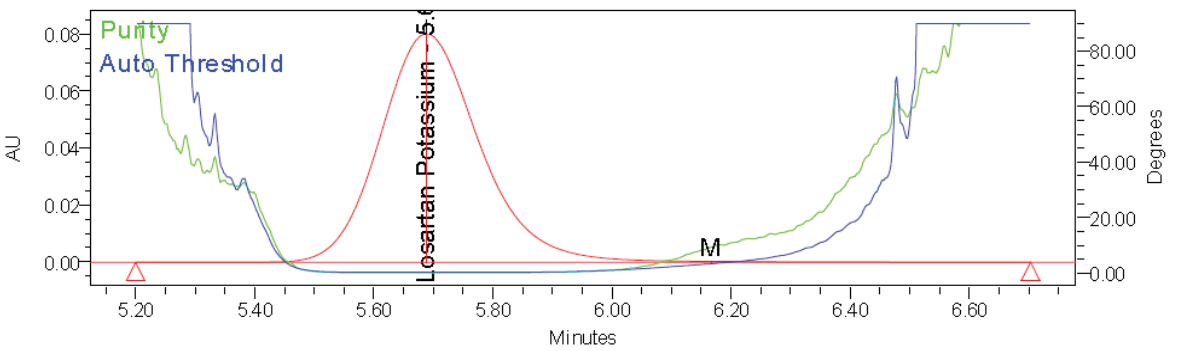

Figure 4: Acid Stress-Purity plot (Green line showed purity angle, Blue line showed purity threshold, Purity angle<Purity threshold means peak is pure).

\section{PurityPlot}

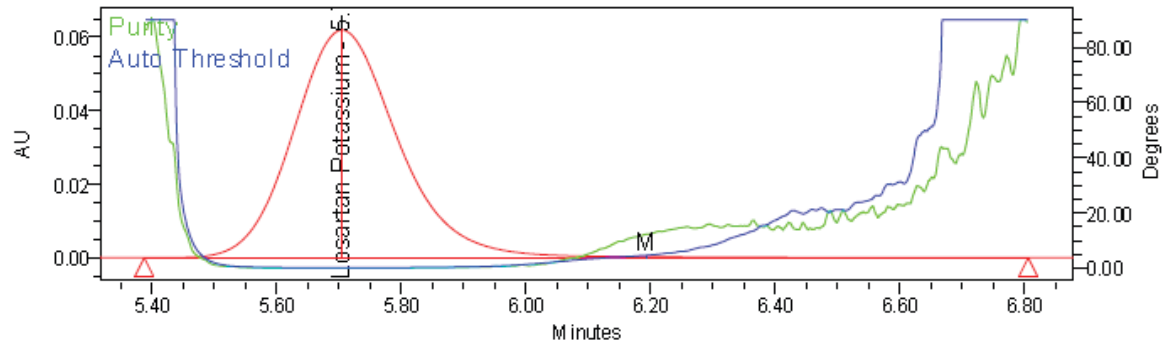

Figure 5: Base Stress-Purity plot(Green line showed purity angle, Blue line showed purity threshold, Purity angle $<$ Purity threshold means peak is pure)

and effect of temperature was observed from ambient to $27^{\circ} \mathrm{C}$. On all these deliberate changes, very minor effect on system suitability was observed and method found robust against these minor changes (Table 6).

\section{Accuracy}

Method accuracy was assessed by comparing the \%RSD of BP method (standard method) with the percentage RSD of the method developed (non-standard method). The RSD for standard method was
$1.012 \%$, while for non-standard method it was $1.516 \%$ and combined RSD of both two methods was found $1.823 \%$ (Table 7 ) that is as per the criteria of precision of bias which should be less than $2 \%$. In order to meet the criteria for practical bias, the mean should be smaller than permissible variation for the respective analyte quantity, which is ideally considered as zero. The results of the study as summarized in the (Table 8 ) shows that the mean is 0.021 that clearly indicated that the method developed was accurate as well as precise $[14,15]$. 
Citation: Latif A, Akbar F, Khan AJ, Shafi H, Mazhar M (2018) Development and Validation of Analytical Method for Quantification of Losartan Potassium in Solid Dosage Form. Pharm Anal Acta 9: 592. doi: 10.4172/2153-2435.1000592

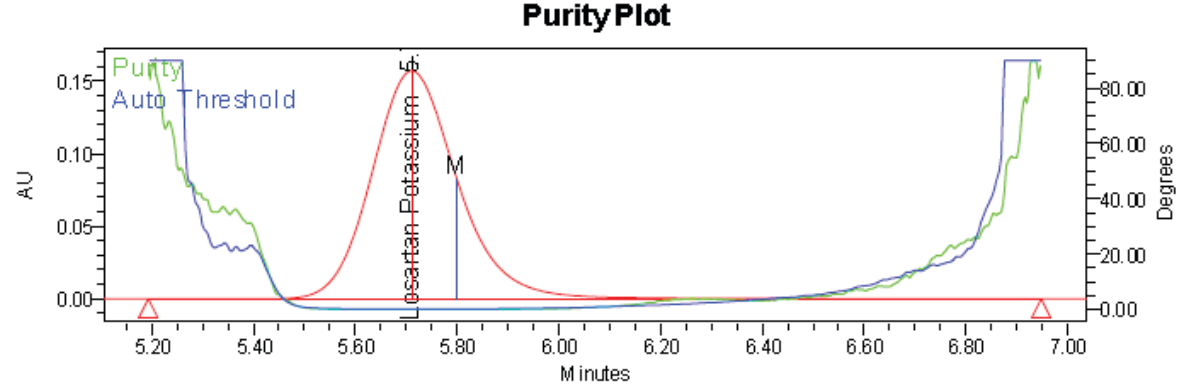

Figure 6: Oxidation Stress-Purity plot (Green line showed purity angle, Blue line showed purity threshold, Purity angle<Purity threshold means peak is pure).

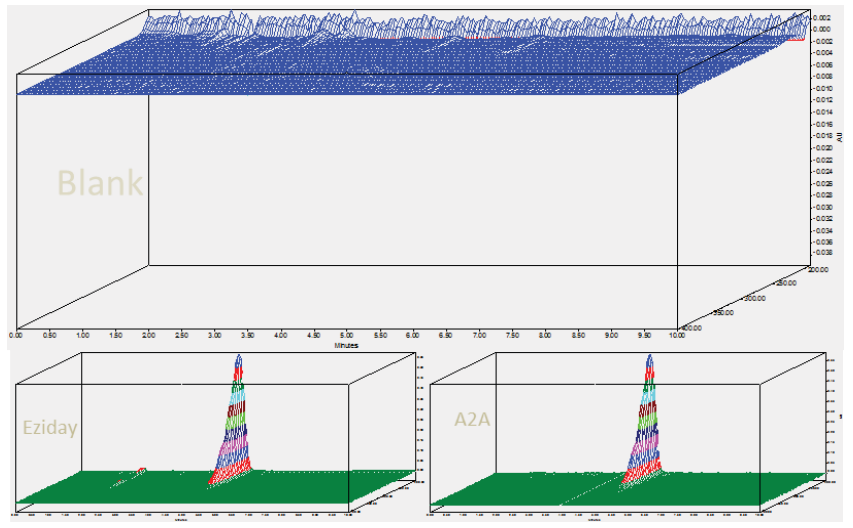

Figure 7: 3D Purity plot.

\begin{tabular}{|c|c|c|c|c|}
\hline Variations & Changes & $\begin{array}{c}\text { Retention } \\
\text { time }\end{array}$ & $\begin{array}{c}\text { Peak } \\
\text { response }\end{array}$ & $\begin{array}{c}\text { Tailing } \\
\text { factor }\end{array}$ \\
\hline $\mathrm{pH}$ & 3.2 & 4.888 & 3071376 & 1.287 \\
\hline Temperature & $27^{\circ} \mathrm{C}$ & 4.734 & 3077245 & 1.199 \\
\hline Flow rate & $0.8 \mathrm{ml} / \mathrm{min}$ & 5.599 & 3064843 & 1.303 \\
\hline \multirow{2}{*}{ Injection volume } & $5 \mathrm{ul}$ & 4.879 & 1500837 & 1.280 \\
\cline { 2 - 5 } & $30 \mathrm{ul}$ & 4.911 & 10902988 & 1.302 \\
\hline Without variation & & 4.877 & 3071376 & 1.200 \\
\hline
\end{tabular}

Table 6: Robustness of Method

\begin{tabular}{|c|c|c|c|c|}
\hline Parameters & \multicolumn{2}{|c|}{ IH method } & \multicolumn{2}{c|}{ BP method } \\
\hline & $\begin{array}{c}\text { Standard } \\
\text { area }\end{array}$ & $\begin{array}{c}\text { Sample } \\
\text { area }\end{array}$ & $\begin{array}{c}\text { Standard } \\
\text { Area }\end{array}$ & $\begin{array}{c}\text { Sample } \\
\text { Area }\end{array}$ \\
\hline Average & 7106168.66 & 7211049 & 6085330.33 & 6304084 \\
\hline Std. Deviation & 124640.19 & 92282.89 & 45385.98 & 80554.14 \\
\hline & 1.753 & 1.279 & 0.746 & 1.278 \\
\hline \%RSD & \multicolumn{2}{|c|}{1.516} & \multicolumn{2}{c|}{1.012} \\
\hline Combined \%RSD & \multicolumn{3}{|c|}{1.823} \\
\hline
\end{tabular}

Table 7: Precision for Bias.

\begin{tabular}{|c|c|c|c|}
\hline Parameters & Assay of IH & Assay of BP & Practical bias \\
\hline Average & 1.0148 & 1.036 & 0.021 \\
\hline Std. Deviation & 0.013 & 0.013 & \\
\hline RSD & 1.280 & 1.278 & \\
\hline
\end{tabular}

Table 8: Practical Bias.

\section{Conclusion}

Authors of this study developed and validated an isocratic method for the determination of Losartan Potassium which is accurate, reproducible, simple and suitable for LK in solid dosage form (Tablets).
Authors used PDA detector in order to determine the peak purity of losartan potassium as well as it proved that degradants and related impurities were also well separated. The present study revealed that RP-HPLC method is more sensitive, stable, rapid and reliable. This method can be successfully employed in pharmaceutical industry in order to minimize the cost and time of analysis.

\section{References}

1. United State Pharmacopoeia 2016.

2. Burnier M, Brunner HR (2000). Angiotensin II receptor antagonists. The Lancet 355: $637-645$.

3. Timmermans PB, Duncia J, Carini D, Chiu A, Wong P, et al. (1995). Discovery of losartan the first angiotensin II receptor antagonist. Journal of human hypertension 9: S3-18.

4. Maio VMDP, Dias CL, Bergold AM, et al. (2005). Validation of an isocratic HPLC assay of losartan potassium in pharmaceutical formulations and stress test for stability evaluation of drug substance. Acta Farm Bonaerense 24: 250-255.

5. Kathiresan K, Gothandaraman S, Manickam SM, Kumar SM, Manavalan R (2008). Analytical method development and validation of losartan potassium tablet by RP-HPLC. Rasayan Journal of Chemistry 1: 521-525.

6. Rao KS, Srinivas K (2010). RP-HPLC method for the determination of losartan potassium and ramipril in combined dosage form. Indian journal of pharmaceutical sciences 72: 108-111.

7. ICH Q2 (R1) European union japan and USA : IICH

8. Blessy M., Patel RD, Prajapati PN, Agrawal Y (2014). Development of forced degradation and stability indicating studies of drugs A review. Journal of Pharmaceutical Analysis 4: 159-165.

9. Hossen MA, Haque MA, Dewan I, Kabir AH, Hossain MK, et al. (2012) Development and validation of RP-HPLC method for the Simultaneous estimation of Hydrochlorothiazide and losartan potassium in tablet Dosage form. Dhaka University Journal of Pharmaceutical Sciences 10: 35-42.

10. Guideline IHT (2005). Validation of analytical procedures. Text and methodology Q2 (R1). 
Citation: Latif A, Akbar F, Khan AJ, Shafi H, Mazhar M (2018) Development and Validation of Analytical Method for Quantification of Losartan Potassium in Solid Dosage Form. Pharm Anal Acta 9: 592. doi: 10.4172/2153-2435.1000592

11. Obando MA, Estela JM, Cerdà V (2008). Simultaneous determination of hydrochlorothiazide and losartan potassium in tablets by high-performance lowpressure chromatography using a multi-syringe burette coupled to a monolithic column. Analytical and bioanalytical chemistry 391: 2349-2356.

12. Bizimana T, Kayumba PC, Védaste K, Egide K, Kaale E, et al. (2016). Development of high performance thin layer chromatography for simultaneous analysis of lamivudine and tenofovir disoproxil fumarate. Rwanda Journal 3 : $6-10$

13. Fuster J, Negro S, Salama A, Fernández-Carballido A, Marcianes $P$, et al (2015). Hplc-uv method development and validation for the quantification of ropinirole in new plgamultiparticulate systems: Microspheres and nanoparticles. International journal of pharmaceutics 491: 310-317.

14. Sistla R, Tata V, Kashyap YV, Chandrasekar D, et al. (2005). Development and validation of a reversed-phase HPLC method for the determination of ezetimibe in pharmaceutical dosage forms. Journal of pharmaceutical and biomedical analysis 39 : $517-522$

15. Shaalan RA, TS Belal (2012). Gradient HPLC-DAD Determination of the Antihypertensive Mixture of Amlodipine Besylate, Valsartan, and Hydrochlorothiazide in Combined Pharmaceutical Tablets. Journal of Liquid Chromatography \& Related Technologies 35: 215-230. 